\title{
Os Rumos que a Reforma Trabalhista Tomará Para Ressignificar o que se (Re)Conhece Como Trabalho: Entre Possibilidades Discursivas e Palavras Retóricas ${ }^{1}$
}

\begin{abstract}
Wilson Engelmann
Pós-Doutor em Direito Público - Direitos Humanos - Centro de Estudios de Seguridad (Ceseg) da Facultad de Derecho da Universidade de Santiago de Compostela, Espanha. Doutor e mestre em Direito pelo Programa de Pós-Graduação em Direito - Unisinos. Coordenador executivo, professor e pesquisador do Mestrado Profissional em Direito da Empresa e dos Negócios. Professor e pesquisador do Programa de Pós-Graduação em Direito - Mestrado e Doutorado, ambos da Unisinos. Bolsista de Produtividade em Pesquisa do CNPq. Líder do Grupo de Pesquisa Jusnano, credenciado junto ao CNPq. http://lattes.cnpq. br/7143561813892945. https://orcid.org/0000-0002-0012-3559wengelmann@unisinos.br.

\section{Guilherme Wünsch}

Pós-doutor em Direito pela PUCRS. Doutor e mestre em Direito pela Unisinos. Professor do Mestrado Profissional em Direito da Empresa e dos Negócios e do Curso de Graduação em Direito, ambos da Unisinos. Acadêmico titular da Cadeira n 26 da Academia Sul-Rio-Grandense de Direito do Trabalho. Advogado. http://lattes.cnpq.br/2498253735871468. http://orcid.org/0000-0002-0012-3559. guilhermeipa@yahoo.com.br
\end{abstract}

RESUMO

Este artigo pretende situar a reforma da legislação do trabalho no cenário da constitucionalização do Direito Privado. Por conta deste movimento, buscar-se á estudar os reflexos da Constituição do Brasil de 1988, ao inaugurar as bases do Estado Democrático de Direito, que procurou, por meio da valorização da livre iniciativa, instalar um sistema econômico capitalista, ao mesmo tempo em que consagrou, em mais de uma oportunidade, a valorização do trabalho humano. Em outras palavras, a ordem econômica social brasileira possui pretensões difíceis de serem concretizadas, posto que esta tem por objetivo conjugar ideias que se encontram em polos opostos, sendo, portanto, tendentes ao afastamento mútuo. Considerando este cenário, os autores farão a análise das possibilidades trazidas pelos pontos cardeais da reforma da legislação trabalhista, que são: flexibilização, geração de empregos, inovação e autonomia, observando as consequências previsíveis para o mercado e o meio ambiente laboral brasileiro. Palavras-chave: Reforma da legislação trabalhista. Direito constitucional do trabalho. Flexibilização. Geração de empregos. Inovação. Autonomia.

\section{THE ROADS THAT THE REFORM OF THE LABOR LAW WILL TAKE TO RESSIGNIFY WHAT IF (RE)KNOWS HOW WORK DOES MEAN: BETWEEN DISCURSIVE POSSIBILITIES AND RETORIC WORDS}

\section{ABSTRACT}

This article intends to situate the reform of labor legislation in the scenario of the constitutionalization of Private Law. The purpose of this movement is to study the reflexes of the Brazilian Constitution of 1988, when it inaugurated the bases of the Democratic State of Right, which sought, through the valorization of free initiative, to implement a capitalist economic system, at the same time as it consecrated, in more than one opportunity, the valuation of human labor. In other words, the Brazilian social economic order has arduous pretensions to be fulfilled, since its aim is to conjugate ideas that are at opposite poles, and, therefore, are tending towards mutual estrangement. Considering this scenario, the authors will analyze the possibilities brought by the cardinal points of the reform of labor legislation, which are: flexibilization, job creation, innovation and autonomy, observing the foreseeable consequences for the Brazilian market and labor environment.

Keywords: Reform of labor legislation. Constitutional labor law. Flexibilization. Generation of Jobs. Innovation. Autonomy.

1 Introdução. 2 A (Re)Estruturação Social do Trabalho como Fundamento de Uma Lógica Protetiva da Figura do Trabalhador. 3 A Reforma Trabalhista e o (Re)Nascimento da Autonomia Privada Como Um Vetor das Relações Entre Empregados e Empregadores. 4 O Sentido do Trabalho Entre a Flexibilização, a Geração de Empregos, a Inovação e a Autonomia Como Pontos Cardeais da Reforma Trabalhista. 4.1 Flexibilização. 4.2 Geração de Empregos. 4.3 Inovação. 4.4 Autonomia. 5 Considerações Finais. 6 Referências.

Recebido em: 8/3/2018

Aceito em: 29/7/2019

\footnotetext{
Este artigo é o resultado parcial da investigação científica desenvolvida pelos autores, no contexto dos seguintes projetos de pesquisa: a) "Sistema do Direito, novas tecnologias, globalização e o constitucionalismo contemporâneo: desafios e perspectivas", Edital Fapergs/Capes 06/2018 - Programa de Internacionalização da Pós-Graduação no RS; b) Chamada Universal MCTIC/CNPq 2018, Faixa 'C': até R\$ 120.000,00, título: “Nanotecnologias e Direitos Humanos observados a partir dos riscos no panorama da comunicação entre o Ambiente Regulatório e o Sistema da Ciência.
} 


\section{Democracia}

Humanos e

\section{INTRODUÇÃO}

O Direito do Trabalho possui uma ligação histórica com o sistema econômico e foi um dos ramos do Direito mais afetados com o fenômeno da globalização, uma vez que suas estruturas estão voltadas à limitação da autonomia da vontade dos particulares. Neste cenário, classicamente desenhado como de interesses antagônicos, o sistema econômico pugnou por um Estado mínimo que apenas garantisse os direitos e liberdades individuais dos cidadãos, atendo-se na intervenção das relações privadas, ao passo que o Estado brasileiro, preocupado em concretizar o princípio da igualdade no plano material, iniciou um processo de constitucionalização do Direito Privado, o qual possui como marco inicial a promulgação da Constituição Federal de $1988 .^{2}$

A partir de 1988 o Brasil, na condição de Estado Democrático de Direito, procurou, mediante a valorização da livre iniciativa, instituir um sistema econômico capitalista, ao mesmo tempo em que consagrou, em mais de uma oportunidade, a valorização do trabalho humano. Em outras palavras, a ordem econômica social brasileira possui pretensões difíceis de serem concretizadas, dado que esta tem por objetivo conjugar ideias que se encontram em polos opostos, sendo, portanto, tendentes ao afastamento mútuo.

Dessa maneira, com vistas a assegurar a instalação do modelo socioeconômico supracitado, possibilitando a comunicação entre o capital e os direitos sociais, o legislador constituinte, no artigo $7^{\circ}, \mathrm{XXVI}$, da CF, veio a reconhecer os acordos e convenções coletivas como fontes normativas autônomas, as quais, mesmo sendo produzidas fora do âmbito de controle do Estado, são reconhecidas por este como normas jurídicas válidas e eficazes, reconhecendo-se a autonomia privada dos particulares para a criação de normas jurídicas. Tal reconhecimento, não por acaso, foi um dos principais pontos de alteração na recente edição da Lei no 13.467 , de 13 de julho de 2017, a chamada Reforma Trabalhista, que se estruturou em um grande mote do negociado sobre o legislado como um caminho pretenso de modernização na relação entre empregados e empregadores.

Com o intuito de promover as aberturas necessárias ao enfrentamento de crises por parte das empresas, bem como para possibilitar uma margem mais ampla de atuação dos entes coletivos, oportunizando a adaptação do contrato de trabalho a situações específicas, 0 legislador constituinte veio, no artigo $7^{\circ}, \mathrm{VI}, \mathrm{XIII}, \mathrm{XIV}$, da CF, a possibilitar que, mediante negociação coletiva, pudessem ser flexibilizadas regras atinentes ao salário e à duração da jornada de trabalho, por exemplo, de tal sorte que este caráter permissivo e flexibilizatório contido na legislação estatal inclina-se a visualizar os empregados e empregadores como equivalentes nos planos jurídico e econômico, de sorte que os contratos de trabalho poderiam ser adaptados para a manutenção da empresa e dos empregos gerados por esta, prestigiando a política de pleno emprego preconizada pela Carta Magna.

\footnotetext{
A Constituição Federal elegeu como princípios fundamentais da República a dignidade da pessoa humana e os valores sociais do trabalho e da livre iniciativa (artigo 1ㅇII, IV, da CF). Além disso, elencou, em seu artigo 5o, os direitos e deveres individuais e coletivos, no artigo 6 o os direitos sociais, no qual o direito ao trabalho se encontra incluído, no artigo 7은 arrolou os direitos objetivos dos trabalhadores e, no artigo 8 o e seguintes, dispôs sobre a liberdade de associação sindical. Ainda, devido à relevância para a observação desse trabalho, o artigo 170 determina que a ordem econômica brasileira seja fundada na valorização do trabalho humano e na livre iniciativa, tendo por fim assegurar a todos os cidadãos uma existência digna, conforme os ditames da justiça social.
} 
Neste contexto, o presente artigo tem por objetivo problematizar os rumos que a Reforma Trabalhista encaminhará o Direito do Trabalho a partir de agora, e, mais do que isso, o que significa o próprio trabalho a partir deste momento histórico que se vive, com uma profunda alteração legislativa, que implicou a modificação de mais de uma centena de artigos contidos na CLT. Para responder a tal questionamento parte-se da premissa de que existem limites à autonomia privada dos particulares, os quais podem ser fixados a partir de uma releitura do Direito do Trabalho sob o prisma constitucional. Será utilizado o método exploratório, a partir da pesquisa bibliográfica, legislativa e jurisprudencial.

\section{A (RE)ESTRUTURAÇÃO SOCIAL DO TRABALHO COMO FUNDAMENTO DE UMA LÓGICA PROTETIVA DA FIGURA DO TRABALHADOR}

Toda a Ciência Jurídica possui um marco temporal de criação, fazendo com que o sistema jurídico, em determinado momento histórico, evolua para responder à crescente complexidade presente na sociedade. ${ }^{3}$ Não é diferente com o Direito do Trabalho, que se constituiu, historicamente, em uma resposta regulatória, diante das alterações dos paradigmas até então vigentes nas sociedades absolutistas, que operavam sob o regime feudal, e que se reorganizavam rumo à modernidade.

O movimento histórico denominado como Revolução Industrial teve o seu início na Inglaterra do século 18 , tendo como a sua característica principal a introdução das máquinas nas indústrias. Dessa forma o trabalho, antes realizado manualmente pelo ser humano, passou a ser feito por intermédio de máquinas, alterando radicalmente o modo de execução do labor, devido às mudanças que emergiram nos meios de produção.

A invenção da máquina e sua aplicação à indústria iriam provocar a revolução nos métodos de trabalho e, consequentemente, nas relações entre patrões e trabalhadores; primeiramente a máquina de fiar, o método de pludlagem (que permitiu preparar o ferro de modo a transformá-lo em aço), o tear mecânico, a máquina a vapor multiplicando a força de trabalho, tudo isso iria importar na redução de mão-de-obra porque, mesmo com o aparecimento das grandes oficinas e fábricas, para obter determinado resultado na produção não era necessário tão grande número de operários ${ }^{4}$ (grifo do autor).

Somando-se a esse cenário expansionista, com a desintegralização do regime de trabaIho feudalista, ocorreu a migração em massa de agricultores em direção aos grandes centros urbanos, configurando-se "um casamento da necessidade de subsistência com a oferta de trabalho" ${ }^{5}$, fato este que permitiu o desenvolvimento inicial da indústria que necessitava de grande quantidade de mão de obra para operar o maquinário recém introduzido no meio fabril.

\footnotetext{
DELGADO, Mauricio Godinho. Curso de direito do trabalho. 9. ed. São Paulo: LTr, 2010. p. 80.

4 VIANA, Segadas. Antecedentes históricos. In: SÜSSEKIND, Arnaldo Lopes et al. Instituições de direito do trabalho. 22. ed. atualizada por Arnaldo Süssekind e João de Lima Teixeira Filho. São Paulo: LTr, 2005. p. 32. v. 1.

GÓIS, Luiz Marcelo Figueiras de. A caminho de um direito trabalhista constitucional. São Paulo: LTr, 2010. p. 25.
} 


\section{Democracia}

Nesse sentido, é que se pode afirmar que houve realmente uma revolução, diante do fato de que, "agora, ao invés do setor primário, a vida econômica mundial transferira-se para o setor secundário, para as indústrias. Daí qualificar-se esse fenômeno como verdadeira revolução, uma Revolução Industrial, que modificou a estrutura produtiva mundial de forma inquestionável."6

Assim sendo, com o advento da Revolução Industrial, o trabalho, até então entendido como sendo apenas o meio pelo qual os seres humanos garantiam a sua subsistência, passa a ser visto de uma nova forma, uma vez que "os trabalhadores, de maneira geral, passaram a trabalhar por salários. Com a mudança, houve uma nova cultura a ser apreendida e uma antiga a ser desconsiderada". ${ }^{7}$

O trabalho subordinado e assalariado entra em cena a partir da reorganização da estrutura social do trabalho, com o surgimento dos papéis sociais ocupados pelas categorias denominadas como capitalistas e proletários, ${ }^{8}$ os quais ocupavam polos opostos na relação de trabalho. De um lado encontravam-se os donos do capital, interessados em auferir a maior quantidade de lucro possível, com a menor contraprestação salarial; no outro polo da relação estavam os empregados, recém-chegados do campo, representando uma mão de obra farta e barata, não contando com nenhuma espécie de proteção legal diante dos empregadores, estando relegados ao trabalho e à remuneração nos termos em que eram oferecidos.

Essa conjuntura é exemplificada por Segadas Viana, que bem representa o espaço ocupado por empregadores e empregados nesse momento da História:

O trabalhador, na sua dignidade fundamental da pessoa humana, não interessava ou preocupava os chefes industriais daquele período. Era a duração do trabalho levada além do máximo da resistência normal do indivíduo. Os salários, que não tinham, como hoje, a barreira dos mínimos vitais, baixavam até onde a concorrência do mercado de braços permitia que eles se aviltassem. Embolsando o trabalhador regularmente as prestações devidas pelo seu trabalho, julgavam os patrões que, assim procedendo, estavam cumprindo integralmente os seus deveres para com esse colaborador principal de sua fortuna crescente. $^{9}$

Dessa forma, este primeiro momento da Revolução Industrial foi marcado pela total ausência de regulação das relações de trabalho. As atividades laborais podiam ser estendidas por mais de 16 horas por dia; mulheres e crianças, que representavam uma mão de obra menos onerosa, ocupavam em grande quantidade o chão das fábricas; não havia higiene ou segurança no ambiente de trabalho. Ou seja, nada importava além do resultado final da produção, e os seres humanos eram vistos como meros objetos nesse processo. ${ }^{10}$

\footnotetext{
GÓIS, Luiz Marcelo Figueiras de. A caminho de um direito trabalhista constitucional. São Paulo: LTr, 2010. p. 25. MARTINS, Sérgio Pinto. Direito do trabalho. 29. ed. São Paulo: Atlas, 2013. p. 6.

MILIBAND, Ralph. Análise de classes. In: GIDDENS, Anthony; TURNER, Jonathan (org.). Teoria social hoje. São Paulo: Unesp, 1999. p. 473.

9 VIANA, Segadas. Antecedentes históricos. In: SÜSSEKIND, Arnaldo Lopes et al. Instituições de direito do trabalho. 22. ed. atualizada por Arnaldo Süssekind e João de Lima Teixeira Filho. São Paulo: LTr, 2005. p. 34. v. 1.

10 GÓIS, Luiz Marcelo Figueiras de. A caminho de um direito trabalhista constitucional. São Paulo: LTr, 2010. p. 27.
} 
Desta maneira, "na doutrina individualista clássica, predominava a teoria da autonomia da vontade, com a maioria das normas dispositivas e não cogentes", ${ }^{11}$ o que trazia quase que uma total liberdade aos particulares para a fixação das condições de contratação. Não havia freios heterônomos relevantes advindos do Estado para regular os limites legais mínimos em que o contrato deveria ser inserido, cabendo somente aos particulares, considerados livres e iguais, produzirem o conteúdo contratual. ${ }^{12}$

Tendo em vista, entretanto, a ausência de uma igualdade material entre as partes, o contrato, baseado tão somente no princípio da igualdade formal, tornou-se um dos principais meios para a exploração dos trabalhadores, pois estes se encontravam em uma posição econômica e social muito aquém daquela que ocupava o empregador. Dessa forma, conforme adverte Pietro Perlingieri, "atrás do encantamento da fórmula, todavia, escondem-se tão somente o liberalismo econômico e a tradução de regras jurídicas de relações de força mercantil". ${ }^{13}$

Diante da hipossuficiência do trabalhador em relação ao empregador, não se podia falar na época em autonomia para a negociação e eleição de cláusulas contratuais, o que vem demonstrar o conteúdo vazio do princípio em tela quando transferido do mundo jurídico para o mundo fático.

Nesse sentido, resta consagrada a lógica da igualdade, como princípio fundamental das Constituições burguesas, mas em seu sentido estritamente formal: todos os homens são iguais perante a lei, não importando que essa igualdade não se concretize no plano substancial, da emancipação social, política e econômica dos desfavorecidos [...] essas revoluções liberais resultaram na progressiva liberação dos servos dos vínculos de servidão e da terra de onde tiravam o seu sustento. Para eles, liberdade passava a significar a possibilidade de venderem livremente sua força de trabalho. Para os donos das terras, liberdade era dispor de sua propriedade como bem entendessem. Com isso, a nova organização socioeconômica era fundada em um duplo conceito de liberdade: a liberdade do trabalho e o livre uso da propriedade e dos meios de produção ${ }^{14}$ (Grifo do autor).

À vista disso, foi em razão da forma como se desenvolveu o novo modelo da relação laboral que acabou o trabalhador ocupando uma condição de hipossuficiência em relação ao empregador, pois foi nas mãos deste último que se concentraram a propriedade, os meios de produção, a matéria-prima e a força de trabalho, restando evidente a sua superioridade econômica em relação aos empregados. Por consequência não havia como se falar em igualdade entre partes contratantes. O trabalhador, na condição de sujeito de direitos passa a ser livre, encontrando, porém, uma limitação dessa liberdade, que insere a sua escolha em uma ordem predeterminada, sendo que "revela-se com isso, uma contradição conceitual, que estabelece, assimetricamente, que o trabalho livre do seio do capitalismo é francamente subordinado aos interesses do capital"15.

11 BARROS, Alice Monteiro. Curso de direito do trabalho. 9. ed. São Paulo: LTr. 2013. p. 53.

12 BARROS, Alice Monteiro. Curso de direito do trabalho. 9. ed. São Paulo: LTr. 2013. p. 53.

13 PERLINGIERI, Pietro. Perfis do direito civil. 3. ed. rev. e ampl. Rio de Janeiro: Renovar, 2002. p. 17.

14 DIAS, Carlos Eduardo Oliveira. Entre os cordeiros e os lobos: reflexões sobre os limites da negociação coletiva nas relações de trabalho. São Paulo: LTr. 2009. p. 29.

15 DIAS, Carlos Eduardo Oliveira. Entre os cordeiros e os lobos: reflexões sobre os limites da negociação coletiva nas relações de trabalho. São Paulo: LTr. 2009. p. 31. 
Diante deste cenário, o "direito do trabalho nasceu sob os influxos do liberalismo econômico e do dogma da autonomia da vontade nas relações entre os particulares, com o consequente afastamento do Estado dessas questões" ${ }^{16}$. Ademais, é com o advento da Revolução Industrial que evidenciamos a formação de dois grupos contrapostos, quais sejam, os trabalhadores e os empresários, os quais se constituem ainda nos dois agrupamentos básicos sobre os quais a economia social moderna no mundo globalizado erige os seus pilares. Como resultado das pressões advindas da classe operária organizada, começam a surgir as primeiras leis de cunho eminentemente trabalhista, que tinham como objetivo principal fixar os limites mínimos a serem observados pelas partes contratantes na relação de emprego.

Este processo de valoração e proteção do trabalho continuou em expansão no decorrer do século 19, podendo-se citar como exemplo a intervenção da Igreja Católica, em 1891, por meio da Encíclica Rerum Novarum, que objetivava uma "fase de transição para a justiça social, traçando regras para a intervenção estatal na relação entre trabalhador e patrão" ${ }^{17}$. Logo, o princípio protetivo ao trabalhador se constituiu no fundamento inicial sobre o qual a legislação trabalhista subsequente se irá apoiar, constituindo-se este, conforme Mauricio Godinho Delgado, na principal justificativa histórica e científica do surgimento desse ramo específico do Direito. ${ }^{18}$

Na primeira metade do século 20 o trabalho, em que pese existirem alguns movimentos descendentes, conseguiu se elevar à condição de direito social, conquistando espaço de valoração positiva nas Constituições ao redor do mundo, diante da sedimentação dos direitos subjetivos e objetivos do trabalhador nestas cartas políticas e na legislação infraconstitucional.

Esta fase inicial de institucionalização e consequente pacificação dos conflitos sociais oriundos do meio trabalhista, porém, não conseguiu uma estabilidade duradoura, pois "um amplo processo de reestruturação dos paradigmas de produção existentes no início da industrialização nos países das primeiras fases do capitalismo ocorreu no quarto final do século XX"19, demonstrando a fragilidade das bases nas quais o Direito do Trabalho se apoiou para a sua construção: a crença na sustentabilidade econômica do modelo de tutela implementado" 20 .

Com vistas à superação dessa problemática histórica na qual o Direito do Trabalho encontra-se inserido, em que a questão dos limites possíveis à expansão da autonomia privada encontra lugar privilegiado na discussão contemporânea e dos próprios rumos que a Reforma Trabalhista traz para a figura do trabalho, é que se procurará compreender de que forma se deve almejar a redução dos custos com mão de obra, garantindo a lucratividade, mas sem que o anseio flexibilizador viole o princípio da irrenunciabilidade, para garantir ao trabalhador um conjunto mínimo de direitos que lhe assegurem o exercício do seu trabalho em condições dignas.

\footnotetext{
SANTOS, Ronaldo Lima dos. Teoria das normas coletivas. 2.ed. São Paulo: LTr, 2009. p. 133.

MARTINS, Sérgio Pinto. Direito do trabalho. 29. ed. São Paulo: Atlas, 2013. p. 8.

18 DELGADO, Mauricio Godinho. Princípios de direito individual e coletivo do trabalho. São Paulo: LTr: 2001. p. 41.

19 DIAS, Carlos Eduardo Oliveira. Entre os cordeiros e os lobos: reflexões sobre os limites da negociação coletiva nas relações de trabalho. São Paulo: LTr, 2009. p. 52.

20 GÓIS, Luiz Marcelo Figueiras de. A caminho de um direito trabalhista constitucional. São Paulo: LTr, 2010. p. 32.
} 


\section{A REFORMA TRABALHISTA E O (RE)NASCIMENTO DA AUTONOMIA PRIVADA COMO UM VETOR DAS RELAÇÕES ENTRE EMPREGADOS E EMPREGADORES}

Recentemente, a edição da Lei N. 13.467, de 13 de julho de 2017, conhecida como Lei da Reforma Trabalhista, firmou-se como uma tentativa de reequilíbrio na relação entre empregado e empregador, pautando-se no postulado da autonomia privada e no intuito de diminuição da excessiva judicialização de demandas trabalhistas. Não raro, este foi um dos pontos constantes da exposição de motivos quando ocorrera a tramitação do Projeto de Lei que originou a redação final do texto hoje vigente. ${ }^{21}$ Trata-se, como referido, de uma tentativa de aproximação do Direito do Trabalho ao Direito Civil, com base no postulado contratual da autonomia entre as partes.

$\mathrm{Na}$ concepção tradicional de contrato, o valor da vontade é um de seus principais elementos, porque baseia-se no fato de que o ser humano, racional por natureza, é livre para contratar, cabendo ao Direito assegurar a livre manifestação de vontade e que as prestações acordadas fossem efetivamente cumpridas pelas partes. ${ }^{22}$

À luz do princípio fundamental da dignidade humana tem-se, de um lado, a técnica das relações jurídicas existenciais, que informam diretamente os chamados direitos da personalidade e, mais amplamente, a tutela da pessoa nas comunidades intermediárias, nas entidades familiares, na empresa, nas relações de consumo e na atividade econômica privada, particularmente no momento da prevenção da lesão, deflagrando, a partir daí, uma transformação profunda na dogmática da responsabilidade civil. A dignidade da pessoa humana, como valor e princípio, compõe-se dos princípios da liberdade privada, da integridade psicofísica, da igualdade substancial e da solidariedade social, todos previstos no artigo 3 으 da Constituição Federal de 1988.

\footnotetext{
${ }^{21}$ De acordo com o texto da exposição de motivos, "no Brasil temos um nível elevado de judicialização das relações do trabalho, o que é retratado pela quantidade de ações trabalhistas que anualmente dão entrada na Justiça do Trabalho. Na grande maioria das ações trabalhistas a demanda reside no pagamento de verbas rescisórias. A falta de canais institucionais de diálogo nas empresas que promovam o entendimento faz com que o trabalhador só venha a reivindicar os seus direitos após o término do contrato de trabalho. Com isso, problemas que poderiam ser facilmente resolvidos no curso do contrato de trabalho vão se acumulando, para serem discutidos apenas ao término do vínculo empregatício, na Justiça do Trabalho". Disponível em: http://www.camara.gov.br/proposicoesWeb/prop_mostrarintegra;jsessionid=A73B0E9C2DD15B2D77E14C33FA9696E7. proposicoesWebExterno2? codteor=1520055\&filename=PL+6787/201. Acesso em: 27 fev. 2018.

$22 \mathrm{O}$ objeto do contrato significa a finalidade perseguida pelas partes, é o norteador para o cumprimento da obrigação assumida pelas partes e se materializa nas características expressas pela doutrina, como a sua licitude, possibilidade e determinabilidade, figuras presentes nos artigos 104 e 166, inciso II, do Código Civil de 2002 (artigo 82, do Código Civil de 1916, demonstrando que se trata de uma ideia já verificada no Direito Civil tradicional). Bussatta considera que o objeto do contrato sempre será, ainda que indiretamente, de conteúdo patrimonial, mas não há a necessidade de que a prestação seja diretamente patrimonial, basta que tenha reflexos no patrimônio da pessoa, ou possa, ainda que por estimativa, ser avaliada pecuniariamente. Já para Lorenzetti, no objeto já está expresso o consentimento, mas deve-se controlar a sua licitude, sua adequação aos valores essenciais do ordenamento jurídico. Para o autor, o que faz o legislador é coordenar a autonomia privada, que encarna propósitos individuais, com os valores coletivos. A forma, por fim, será o elemento externo que tornará possível o reconhecimento da manifestação da vontade, no sentido de se compreender que o contrato efetivamente existe no campo concreto. Considerando os princípios e elementos que formam a concepção tradicional de contrato, é possível se chegar aos quatro apontamentos seguintes: a) o contrato é substancialmente constituído pelo elemento da vontade, produto da autonomia das partes; b) o contrato é um conceito normativo e que pressupõe a manifestação voluntária da vontade pelos sujeitos; c) o contrato é um ato jurídico bilateral cuja finalidade é criar, modificar e extinguir direitos e d) o contrato foi entendido pela teoria clássica como um fenômeno econômico. Para maior aprofundamento desta leitura, recomenda-se: BUSSATTA, Eduardo Luiz. Elementos. In: MORRIS, Amanda Zoe; BARROSO, Lucas Abreu (coord.). Direito dos contratos: teoria contratual - contratos em espécie. São Paulo: Revista dos Tribunais, 2008. p. 56. LORENZETTI, Ricardo Luís. Fundamentos do direito privado. São Paulo: RT, 1998. p. 550.
} 


\section{Humanos}

Democracia

A dignidade da pessoa humana há de ser tutelada e promovida, em última análise, nos espaços públicos e privados, daí resultando a imprescindibilidade de um controle da atividade econômica segundo os valores constitucionais, processo hermenêutico que, em definitivo, há de ser intensificado - e jamais arrefecido - com a promulgação de leis infraconstitucionais. ${ }^{23}$ O desafio do jurista de hoje consiste precisamente na harmonização das fontes normativas, a partir dos valores e princípios constitucionais.

Em tal perspectiva, a Reforma Trabalhista deveria ter como preocupação as novas dimensões do próprio mercado de trabalho, mediante um modelo econômico disruptivo, que rompe com a lógica tradicional para uma economia com forte presença das tecnologias digitais e conectividade das pessoas, por exemplo, o caso do Uber. Cuida-se, na verdade, de uma necessidade imposta ao Direito do Trabalho para a modificação de um modelo estanque rumo a um modelo de flexibilização.

O Direito do Trabalho deixa de operar de maneira fechada, abrindo-se em direção à comunicação com as demais regras do sistema, em que os princípios e as regras presentes na Constituição ocupam o lugar superior na escala hierárquica normativa, informando todo o sistema legal que abaixo destes se encontram. Nesta esteira comunicativa, cumpre ressaltar a existência do artigo $611-\mathrm{A},{ }^{24}$ da CLT, no tocante a diversas possibilidades de prevalência dos acordos coletivos em detrimento ao legislado.

Não se pode deixar de engrandecer a tentativa do legislador de estabelecer um catálogo acerca das possibilidades negociais entre as partes. Verifica-se, porém, que muitos pontos deste rol não deveriam ser catalogados como passíveis de negociação, como jornada de trabalho, registro de banco de horas, adicional de insalubridade, conquanto se saiba que, na realidade, o empregado possui um baixo poder de efetiva negociação sobre tais aspectos na sua relação empregatícia, mormente porque basicamente adere às condições de trabalho quando de sua admissão.

\footnotetext{
23 TEPEDINO, Gustavo. Normas constitucionais e Direito Civil. Revista da Faculdade de Direito de Campos, ano IV, no 4 e ano V, no 5 , p. 174, 2003-2004

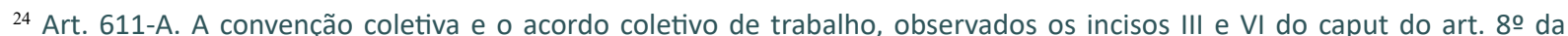
Constituição, têm prevalência sobre a lei quando, entre outros, dispuserem sobre: I - pacto quanto à jornada de trabalho, observados os limites constitucionais; II - banco de horas anual; III - intervalo intrajornada, respeitado o limite mínimo de trinta minutos para jornadas superiores a seis horas; IV - adesão ao Programa Seguro-Emprego (PSE), de que trata a Lei $n$ 13.189, de 19 de novembro de 2015; $V$ - plano de cargos, salários e funções compatíveis com a condição pessoal do empregado, bem como identificação dos cargos que se enquadram como funções de confiança; $\mathrm{VI}$ - regulamento empresarial; VII - representante dos trabalhadores no local de trabalho; VIII - teletrabalho, regime de sobreaviso, e trabalho intermitente; IX - remuneração por produtividade, incluídas as gorjetas percebidas pelo empregado, e remuneração por desempenho individual; $\mathrm{X}$ - modalidade de registro de jornada de trabalho; XI - troca do dia de feriado; XII - enquadramento do grau de insalubridade e prorrogação de jornada em locais insalubres, incluída a possibilidade de contratação de perícia, afastada a licença prévia das autoridades competentes do Ministério do Trabalho, desde que respeitadas, na integralidade, as normas de saúde, higiene e segurança do trabalho previstas em lei ou em normas regulamentadoras do Ministério do Trabalho; XIII - (Revogado Medida Provisória no 808, de 2017); XIV - prêmios de incentivo em bens ou serviços, eventualmente concedidos em programas de incentivo; XV - participação nos lucros ou resultados da empresa.
} 
Como forma de limitar as críticas a este artigo, o legislador optou pela criação do artigo 611-B, ${ }^{25}$ com um catálogo de direitos que não podem ser objeto de negociação entre empregados e empregadores. Este artigo, acrescido na CLT por ocasião da Reforma Trabalhista, é, na verdade, ilusório. Primeiro, porque é flagrante a dicotomia com o artigo 611-A, quando, por exemplo, veda a negociação sobre regras de higiene e segurança do trabalho, ao passo que o artigo 611-A autoriza negociar regras de jornada, banco de horas e adicional de insalubridade, que justamente são vertentes da saúde laboral. Segundo, porque o artigo 611-B é cópia do artigo 7ํ da Constituição Federal, no seu âmago. Ou seja, a CLT está vedando, em 2017, a negociação sobre aspectos que desde 1988 já estavam vedados. É a falsa crença de que existem limites dados pela Reforma, quando ela na verdade só vem a autorizar a negociação e, não, limitá-la.

Por outro lado, um dos aspectos que a Reforma Trabalhista trouxe, e que, de certa forma, atende a um anseio dos empregadores e empregados, é a extinção do contrato de trabalho por mútuo acordo, este, sim, um típico exemplo de exercício da autonomia entre as partes da relação empregatícia, consoante se verifica da redação do novo artigo $484-A,{ }^{26}$ da CLT. Destaca-se que a legislação assegura a percepção dos direitos trabalhistas do empregado, com a ressalva do aviso prévio indenizado e da multa do FGTS, em que ambos serão pagos por metade.

\footnotetext{
${ }^{25}$ Art. 611-B. Constituem objeto ilícito de convenção coletiva ou de acordo coletivo de trabalho, exclusivamente, a supressão ou a redução dos seguintes direitos: I - normas de identificação profissional, inclusive as anotações na Carteira de Trabalho e Previdência Social; II - seguro-desemprego, em caso de desemprego involuntário; III - valor dos depósitos mensais e da indenização rescisória do Fundo de Garantia do Tempo de Serviço (FGTS); IV - salário mínimo; V - valor nominal do décimo terceiro salário; VI - remuneração do trabalho noturno superior à do diurno; VII - proteção do salário na forma da lei, constituindo crime sua retenção dolosa; VIII - salário-família; IX - repouso semanal remunerado; X - remuneração do serviço extraordinário superior, no mínimo, em 50\% (cinquenta por cento) à do normal; XI - número de dias de férias devidas ao empregado; XII - gozo de férias anuais remuneradas com, pelo menos, um terço a mais do que o salário normal; XIII - licença-maternidade com a duração mínima de cento e vinte dias; XIV - licença-paternidade nos termos fixados em lei; XV - proteção do mercado de trabalho da mulher, mediante incentivos específicos, nos termos da lei; XVI - aviso prévio proporcional ao tempo de serviço, sendo no mínimo de trinta dias, nos termos da lei; XVII - normas de saúde, higiene e segurança do trabalho previstas em lei ou em normas regulamentadoras do Ministério do Trabalho; XVIII - adicional de remuneração para as atividades penosas, insalubres ou perigosas; XIX - aposentadoria; XX - seguro contra acidentes de trabalho, a cargo do empregador; XXI - ação, quanto aos créditos resultantes das relações de trabalho, com prazo prescricional de cinco anos para os trabalhadores urbanos e rurais, até o limite de dois anos após a extinção do contrato de trabalho; XXII - proibição de qualquer discriminação no tocante a salário e critérios de admissão do trabalhador com deficiência; XXIII - proibição de trabalho noturno, perigoso ou insalubre a menores de dezoito anos e de qualquer trabalho a menores de dezesseis anos, salvo na condição de aprendiz, a partir de quatorze anos; XXIV - medidas de proteção legal de crianças e adolescentes; XXV - igualdade de direitos entre o trabalhador com vínculo empregatício permanente e o trabalhador avulso; XXVI - liberdade de associação profissional ou sindical do trabalhador, inclusive o direito de não sofrer, sem sua expressa e prévia anuência, qualquer cobrança ou desconto salarial estabelecidos em convenção coletiva ou acordo coletivo de trabalho; XXVII - direito de greve, competindo aos trabalhadores decidir sobre a oportunidade de exercê-lo e sobre os interesses que devam por meio dele defender; XXVIII - definição legal sobre os serviços ou atividades essenciais e disposições legais sobre o atendimento das necessidades inadiáveis da comunidade em caso de greve; XXIX - tributos e outros créditos de terceiros; XXX - as disposições previstas nos arts. 373-A, 390, 392, 392-A, 394, 394-A, 395, 396 e 400 desta Consolidação. Parágrafo único. Regras sobre duração do trabalho e intervalos não são consideradas como normas de saúde, higiene e segurança do trabalho para os fins do disposto neste artigo.

${ }^{26}$ Art. 484-A. O contrato de trabalho poderá ser extinto por acordo entre empregado e empregador, caso em que serão devidas as seguintes verbas trabalhistas: I - por metade: a) o aviso prévio, se indenizado; e b) a indenização sobre o saldo do Fundo de Garantia do Tempo de Serviço, prevista no $\S 1^{\circ}$ do art. 18 da Lei no 8.036, de 11 de maio de 1990; II - na integralidade, as demais verbas trabalhistas. §10 A extinção do contrato prevista no caput deste artigo permite a movimentação da conta vinculada do trabalhador no Fundo de Garantia do Tempo de Serviço na forma do inciso I-A do art. 20 da Lei no 8.036, de 11 de maio de 1990, limitada até 80\% (oitenta por cento) do valor dos depósitos. §2으 A extinção do contrato por acordo prevista no caput deste artigo não autoriza o ingresso no Programa de Seguro-Desemprego.
} 
O aspecto que mais chama a atenção, contudo, é que esta modalidade de extinção do contrato de trabalho não autoriza o saque integral da conta vinculada do FGTS, nem a percepção do seguro-desemprego por parte do empregado, em situação igual ao que ocorre na extinção do contrato de trabalho intermitente. Pensa-se que, neste ponto, torna-se dever do empregador dar ciência ao empregado acerca de tal situação, como decorrência da boa-fé que deve permear a relação de confiança entre ambas as partes, para que o empregado não seja surpreendido com o ato, pensando que poderá ter acesso a direitos que a Reforma Trabalhista não concedeu. Do contrário, poder-se-ia pensar, até mesmo, na nulidade da extinção por vício de consentimento pautado no artigo 9o da CLT, quando dispõe que serão nulos de pleno direito os atos praticados com o objetivo de desvirtuar, impedir ou fraudar a aplicação dos preceitos contidos na Consolidação das Leis do Trabalho.

Há um novo olhar do Direito do Trabalho pela ciência jurídica, fazendo com que o dogma da autonomia da vontade comece a ser flexibilizado, pois não mais poderia servir o contrato como instrumento de realização meramente individual. O contexto e os aspectos valorativos passam a ser tomados em consideração na relação contratual. ${ }^{27}$

Como premissa inicial, tem-se que o princípio da função social, antes de mais nada, "significa muito simplesmente que o contrato não deve ser concebido como uma relação jurídica que só interessa às partes contratantes, impermeável às condicionantes sociais que o cercam e que são por ele próprio afetados" 28 , passando a ser necessário a verificação dos reflexos do contrato no meio social, bem como se estes se adéquam aos novos princípios e regras presentes na Constituição Federal de 1988. ${ }^{29}$

Pode-se afirmar que os contratantes possuem, a partir de uma perspectiva de um direito privado constitucionalizado, o dever "de atender - ao lado dos próprios interesses individuais perseguidos pelo regulamento contratual - a interesses extracontratuais socialmente relevantes, dignos de tutela jurídica, que se relacionam com o contrato ou são por ele atingidos". ${ }^{30}$ No Direito do Trabalho, dada a autonomia científica da disciplina, bem como diante de sua característica fundante protecionista que impede o livre exercício da autonomia da von-

\footnotetext{
${ }^{27}$ A nova concepção de contrato é uma concepção social deste instrumento jurídico, para a qual não só o momento da manifestação da vontade (consenso) importa, mas onde também e principalmente os efeitos do contrato na sociedade serão levados em conta e onde a condição social e econômica das pessoas nele envolvidas ganha em importância. MARQUES, Cláudia Lima. Contratos no Código de Defesa do Consumidor: o novo regime das relações contratuais. 3. ed. São Paulo: Revista dos Tribunais, 1998, p. 101 (Biblioteca de direito do consumidor, v. 1).

28 NEGREIROS, Teresa. Teoria do Contrato: novos paradigmas. 2. ed. Rio de Janeiro: Renovar, 2006. p. 208.

${ }^{29}$ O contrato assume função social e é visto como um dos fenômenos integrantes da ordem econômica, nesse contexto visualizado como um fator submetido aos princípios constitucionais da justiça social, solidariedade, livre concorrência, liberdade de iniciativa, etc., que fornecem os fundamentos para uma intervenção no âmbito da autonomia contratual. AGUIAR JUNIOR, Ruy Rosado. "A boa-fé na relação de consumo". Revista de Direito do Consumidor, São Paulo: Revista dos Tribunais, n. 14, p. 20-32, p. 22-23, abr./jun. 1995.

30 TEPEDINO, Gustavo. "Crise das fontes normativas e técnica legislativa na Parte Geral do Código Civil de 2002". TEPEDINO, Gustavo (org.). A parte geral do novo código civil: estudos nas perspectiva civil-constitucional. 2. ed. Rio de Janeiro: Renovar, 2003. p. 31.
} 
tade pelas partes, ${ }^{31}$ o princípio da função social irá incidir de modo bastante particular. Assim, tanto no contrato individual como nos acordos e convenções coletivas de trabalho, os reflexos desses contratos passam a ser verificados no contexto social, bem como se a dignidade humana e os direitos fundamentais das partes estão sendo respeitados nessa relação contratual.

O trabalho estabeleceu-se na modernidade como a mola propulsora de todo o progresso social, gerando riqueza e prosperidade para o meio em que as atividades econômicas se desenvolvem. O ser humano, na condição de trabalhador, constitui-se no princípio e fim de todo o trabalho realizado na sociedade, produzindo e, concomitantemente, consumindo uma enorme gama de material gerado por meio do labor sob o regime capitalista.

O trabalho, assim, exerce a mais importante função social nas sociedades capitalistas globalizadas, sem o qual não poderia o atual sistema continuar em funcionamento.

A centralidade do trabalho - e, em especial, sua forma mais articulada e comum no capitalismo, o emprego - torna-se o epicentro da organização da vida social e econômica. Percebe tal matriz a essencialidade da conduta laborativa como um dos instrumentos mais relevantes da afirmação do ser humano, quer no plano de sua própria individualidade, quer no plano de sua inserção familiar, social e econômica. A centralidade do trabalho em todos os níveis da vida da ampla maioria das pessoas é percebida por esta matriz cultural, com notável sensibilidade social e ética, erigindo-se como um dos pilares principais de estruturação da ordem econômica, social e cultural de qualquer sociedade capitalista que se queira minimamente democrática. ${ }^{32}$

Em grande parte, as dificuldades de se estabelecer os limites da autonomia privada, e, consequentemente, a sua função social, deve-se ao fato de que a Constituição Federal brasileira, ao regular os aspectos referentes à ordem econômica, adota um sistema híbrido, conjugando a livre iniciativa com a justiça social. ${ }^{33}$ No caso do ramo trabalhista, resta bastante clara essa característica bipolar do sistema adotado pelo constituinte, pois este assegura à iniciativa privada a criação de normas jurídicas trabalhistas pela via autônoma, ao mesmo tempo que cria um núcleo rígido de direitos irrenunciáveis dos trabalhadores.

Exemplo dessa característica híbrida da ordem econômica brasileira a influenciar as normas de Direito do Trabalho manifesta-se no artigo $7^{\circ}, \mathrm{VI}, \mathrm{XIII}, \mathrm{XIV}$, no qual o legislador constituinte previu que os salários são irredutíveis, que a jornada de trabalho resta fixada em 8 horas diárias e 44 semanais, sendo facultada a compensação de horário, e que o trabalho, em

\footnotetext{
${ }^{31}$ Embora haja uma forte interferência e não exista exatamente autonomia da vontade entre empregado e empregador, há um sistema de proteção ao trabalhador, de forma que as normas de ordem pública incidem automaticamente sobre o contrato de trabalho, restringindo a autonomia da vontade dos sujeitos do pacto laboral. [...] A relação entre empregado e empregador não é igual, por isso há a necessidade de proteção ao economicamente mais fraco, visando a equilibrar a relação entre os envolvidos e evitar abusos do poder econômico, de forma que o empregador não imponha sua vontade ao empregado. MARTINS, Sérgio Pinto. Direito do trabalho. 29. ed. São Paulo: Atlas, 2013. p. 103.

32 DELGADO, Mauricio Godinho. Capitalismo, trabalho e emprego: entre o paradigma da destruição e os caminhos da reconstrução. São Paulo: LTr, 2006. p. 29.

${ }^{33}$ A tensão entre liberdade individual e solidariedade social - especificada, em relação à ordem econômica, no conflito entre a livre iniciativa e a justiça social - não se resolve com recurso à normativa constitucional. Ao contrário, está ali, na própria Constituição Federal, a fonte da tensão. Com efeito, a ordem econômica (artigo 170 et seq..), na qual se insere a ordem contratual, caracteriza-se por tentar articular a livre iniciativa com a justiça social. NEGREIROS, Teresa. Teoria do contrato: novos paradigmas. 2. ed. Rio de Janeiro: Renovar, 2006. p. 286.
} 
turnos ininterruptos de revezamento, tem jornada especial de 6 horas, positivando, em cada uma dessas hipóteses, a possibilidade de incidência de negociações coletivas, possibilitando a flexibilização das normas de ordem pública.

Ao limitar, por exemplo, a jornada de trabalho e ao determinar a irredutibilidade dos salários, a Constituição Federal demonstra a preocupação com a pessoa humana do trabalhador e com a sua inserção qualitativa na sociedade, todavia, ao permitir a flexibilização de duas regras de extrema importância,

[...] temos frontalmente atingido o próprio Direito do Trabalho, porquanto ele foi construído a partir de um processo intenso de lutas e de conflitos sociais, a fim de serem estabelecidos padrões mínimos que impeçam que a classe trabalhadora, sobrepujada economicamente, fique à mercê das injunções estabelecidas pelos donos dos meios de produção. ${ }^{34}$

Por outro lado, o legislador constituinte vem a atender com essas hipóteses de flexibilização positivadas uma histórica "reivindicação empresarial identificável com uma explícita solicitação de menores custos sociais e maior governabilidade do fator trabalho" ${ }^{35}$, adaptando a atividade empresarial às flutuações constantes do mercado.

Em suma, a Constituição Federal busca a difícil missão de garantir, primeiramente, a dignidade da pessoa humana do trabalhador, e, para tanto, precisa promover a conciliação do valor social do trabalho e da livre iniciativa, possibilitando incluir a pessoa humana no contexto social capitalista de produção, inserindo esta conjuntura em um cenário de um Estado Democrático de Direito.

\section{SENTIDO DO TRABALHO ENTRE A FLEXIBILIZAÇÃO, A GERAÇÃO DE EMPREGOS, A INOVAÇÃO E A AUTONOMIA COMO PONTOS CARDEAIS DA REFORMA TRABALHISTA}

O Direito do Trabalho, entendido como um conjunto de regras que visa a garantir os direitos fundamentais dos trabalhadores, encontra-se em permanente contato com o sistema econômico, o qual exerce pressão permanente no sentido da desregulamentação das leis trabalhistas, observando-se que nenhum dos dois pode existir, em um sistema capitalista, sem a presença do outro. ${ }^{36} \mathrm{~A}$ adaptação de um direito de matriz individualista ${ }^{37}$ para um outro, que privilegie a função social de seus institutos, se traduz em um processo em que os avanços no plano teórico necessitam de aplicação no espaço social, o que depende de uma evolução dos mecanismos de solução de conflitos na sociedade, na qual o princípio da autonomia privada

\footnotetext{
${ }^{34}$ DIAS, Carlos Eduardo Oliveira. Entre os cordeiros e os lobos: reflexões sobre os limites da negociação coletiva nas relações de trabalho. São Paulo: LTr. 2009. p. 155.

${ }^{35}$ BARROS, Alice Monteiro. Curso de direito do trabalho. 9. ed. São Paulo: LTr. 2013. p. 69.

${ }^{36}$ GÓIS, Luiz Marcelo Figueiras de. A caminho de um direito trabalhista constitucional. São Paulo: LTr, 2010. p. 71.

${ }^{37}$ É hoje plenamente aceito, no entanto, que a realidade das relações interprivadas não mais se concilia com perspectivas segundo as quais o Direito Civil, que as regula, teria como objeto discriminante a disciplina de um indivíduo assim abstrato, partícipe de relações jurídicas axiomaticamente fundadas sobre uma igualdade meramente formal. Especialmente no campo do Direito Contratual, a coerência da lógica individualista é incapaz de resistir ao confronto com a realidade e com os problemas postos pelas tão manifestas quanto profundas desigualdades sociais. NEGREIROS, Teresa. Teoria do contrato: novos paradigmas. 2. ed. Rio de Janeiro: Renovar, 2006. p. 5.
} 
assume papel de vanguarda nesse processo emancipatório, permitindo aos grupos representados que negociem os seus interesses, agora, também, necessariamente atentos à função social dos acordos e convenções coletivas no contexto maior da sociedade.

Dessa forma, constando que a empresa cumpre a sua função social, conforme preconizado no artigo 170, III, da CF, gerando empregos e agindo de boa-fé com os seus empregados, ${ }^{38}$ diante de uma crise financeira estariam autorizados os representantes de classe a encontrarem a melhor saída para que a atividade econômica se mantivesse viável, mesmo que, para isso, tivesse de ser reduzido, momentaneamente, o patrimônio jurídico do trabalhador. É em tal contexto que quatro pontos surgem como norteadores da aplicação da Reforma TrabaIhista, tal como pontos cardeais na bússola, como tentativa de dar um norte à segurança jurídica na aplicação da nova legislação que, na verdade, ainda poderá sofrer mudanças diante da incerteza quanto à transformação em lei da Medida Provisória N. 808, de 2017.

\subsection{Flexibilização}

O tema da flexibilização sempre foi uma das principais controvérsias caras ao Direito do Trabalho, no sentido de se privilegiar a autonomia entre as partes, o que, de certa forma, encontrava-se esquecido no campo prático, especialmente porque se tinha uma atuação mais fortalecida dos sindicatos no tocante às negociações coletivas, representando os interesses das categorias, de modo que a negociação individual não era um marco ao Direito do TrabaIho, o que vem modificado pela Reforma.

Nos casos de flexibilização do contrato de trabalho, a dignidade humana do trabalhador não poderá ser sobrepujada. É notório que a manutenção do emprego, em detrimento de uma pequena redução de seu patrimônio jurídico em determinada situação pontual, traz prejuízos menores a sua dignidade do que a perda definitiva do posto de trabalho poderia acarretar.

Nos demais casos, porém, nos quais acordos e convenções coletivas de trabalho são pactuados com o intuito de flexibilizar normas estatais de ordem pública, como aquelas que visam a assegurar a salubridade e a segurança no ambiente de trabalho, deve incidir o princípio de direito individual do trabalho da inalterabilidade contratual lesiva, ${ }^{39}$ nos termos do artigo 468 da $\mathrm{CLT}^{40}$ com o afastamento da norma coletiva acordada in pejus, e com o retorno a situação jurídica originária. ${ }^{41}$

\footnotetext{
${ }^{38}$ GÓIS, Luiz Marcelo Figueiras de. A caminho de um direito trabalhista constitucional, op. cit., p. 137.

39 DELGADO, Mauricio Godinho. Curso de direito do trabalho, op. cit., p. 188.

${ }^{40}$ Art. 468 - Nos contratos individuais de trabalho só é lícita a alteração das respectivas condições por mútuo consentimento, e ainda assim desde que não resultem, direta ou indiretamente, prejuízos ao empregado, sob pena de nulidade da cláusula infringente desta garantia. BRASIL. Lei № 5.452, de 1ㅇ de maio de 1943. Aprova a Consolidação das Leis do Trabalho. Disponível em: http://www.planalto.gov.br/ccivil_03/decreto-lei/Del5452.htm. Acesso em: 28 dez. 2017.

${ }^{41}$ Temos, portanto, que o ordenamento jurídico trabalhista estabelece a regra de possibilidade de ajuste entre as partes, ou de fixação pelo legislador de direitos e obrigações, mas sempre respeitado o mínimo garantido aos trabalhadores. Em síntese, pode-se estabelecer condições mais favoráveis ao trabalhador, mas não se pode retirar as garantias mínimas asseguradas. MANUS, Pedro Paulo Teixeira. Negociação coletiva e contrato individual de trabalho. São Paulo: Atlas, 2001. p. 116.
} 


\section{Democracia}

Humanos e

Tal situação vem corroborada pelo princípio de direito coletivo do trabalho denominado como princípio da adequação setorial negociada, o qual, como se viu, estabelece que as normas de origem coletiva somente irão prevalecer sobre as normas estatais quando instituírem direitos em um padrão superior do que o previsto pelo legislador, sendo necessário, ainda, que as normas criadas pela via autônoma tratem de direitos revestidos de caráter de disponibilidade, como é o caso daquelas hipóteses em que o legislador expressamente previu a possibilidade de flexibilização mediante a negociação coletiva. ${ }^{42}$

A garantia da prevalência dos limites de ordem pública decorre, justamente, das escoIhas valorativas realizadas pelo legislador constituinte, bem como do princípio da gradação da positividade jurídica, o qual coloca a Constituição no topo da hierarquia normativa do sistema jurídico brasileiro, ressaltando-se que as normas coletivas, ao entrarem em choque com as diretrizes constitucionais, não podem prevalecer dado o grau inferior que ocupam na escala de valor normativo. ${ }^{43}$

Pode-se afirmar, portanto, que, diante dos valores consagrados na Carta Magna, as normas coletivas cumprem a sua função social quando conseguem, apesar de todas as dificuldades desse processo, promover a conciliação entre o valor social do trabalho e da livre iniciativa, sempre em compasso com a dignidade humana do trabalhador. As últimas décadas evidenciaram que o trabalho passou por um processo de transformação, com significativas repercussões nos países em desenvolvimento, mormente naqueles de industrialização imediata. Ao mesmo tempo em que não se vislumbrou mais um trabalhador fabril, proletário, cresceu aquele trabalhador que se pode chamar de subproletário, assujeitado a condições precárias de trabalho, como na terceirização, em contratações informais, que amplificaram a fragmentação que o próprio trabalho passou com a criação de múltiplas categorias.

É certo que a Reforma Trabalhista pretende a ampliação do âmbito negocial, privilegiando-se o chamado negociado sobre o legislado. Trata-se de uma leitura cautelosa que se deve fazer. A negociação não pode e nem deve, sob pena de afronta ao artigo 9o da CLT, servir para a renúncia ou diminuição de direitos. Há limitações constitucionais que devem ser respeitadas, assim como todo o sentido do princípio da prevalência da norma mais benéfica, o qual determina a aplicação da fonte do Direito que seja mais vantajosa ao empregado.

\subsection{Geração de Empregos}

Um dos grandes chamativos da Reforma Trabalhista, à época de sua elaboração, foi o discurso de necessidade de mudança da legislação trabalhista para o aumento do número de empregos no Brasil, diante do cenário de crise econômica que atingia o mercado.

\footnotetext{
42 Pelo princípio da adequação setorial negociada as normas autônomas juscoletivas construídas para incidirem sobre determinada comunidade econômico-profissional podem prevalecer sobre o padrão geral heterônomo justrabalhista desde que respeitados certos critérios objetivamente fixados. São dois esses critérios autorizativos: a) quando as normas autônomas juscoletivas implementam um padrão setorial de direitos superior ao padrão geral oriundo da legislação heterônoma aplicável; b) quando as normas autônomas juscoletivas transacionam setorialmente parcelas justrabalhistas de indisponibilidade apenas relativa (e não de indisponibilidade absoluta). DELGADO, Mauricio Godinho. Curso de direito do trabalho, op. cit., p. 1.229.

${ }^{43}$ SANTOS, Ronaldo Lima de. Teoria das normas coletivas. 2. ed. São Paulo: LTr, 2009. p. 57.
} 
Sobre a questão da empregabilidade, refere Ricardo Antunes que a década de 80 presenciou, nos países de capitalismo avançado, profundas transformações no mundo do trabaIho, nas suas formas de inserção na estrutura produtiva, nas formas de representação sindical e política. Foram tão intensas as modificações que se pode mesmo afirmar terem os trabalhadores ${ }^{44}$ presenciado a mais aguda crise daquele século, que não só atingiu a sua materialidade, mas teve profundas repercussões na sua subjetividade e, no íntimo inter-relacionamento desses níveis, afetou a sua forma de ser.

A forma de produção do capital adaptou-se à emergência de um novo processo de trabalho, em que não apenas o tempo e a produção são fatores de avaliação, mas a flexibilização dos padrões, com novos modelos de busca de produtividade, virou sinônimo de uma gestão de trabalho. Neste sentido, novamente as palavras de Antunes, quando explica que de um lado verificou-se uma desproletarização do trabalho industrial, fabril, manual, especialmente (mas não só) nos países de capitalismo avançado. Por outro lado, ocorreu um processo intensificado de subproletarização, presente na expansão do trabalho parcial, precário, temporário. Efetivou-se, também, uma expressiva terceirização do trabalho, em diversos setores produtivos, bem como uma enorme ampliação do assalariamento no setor de serviços. ${ }^{45}$

Desta forma, inobstante todo o desenvolvimento tecnológico que permeia as relações modernas de trabalho, verifica-se a ainda existente desqualificação de formas de trabalho, demonstrando que esta pretensa atualização das relações entre empregado e empregador não parece que fará desaparecer esta classe-que-vive-do-trabalho, para se usar aqui a expressão referida anteriormente. Os trabalhadores não se enxergam como sujeitos em um processo de negociações diretas com os empregadores, ou até mesmo por seus sindicatos, porque a lógica ainda presente no trabalho dos dias atuais não é a que busca a qualificação de tais relações, mas a que mantém a centralidade do poder nas mãos do empregador.

$O$ que se tem verificado neste momento é o aumento da informalidade como simulador de um crescimento do número de empregos no Brasil. Em recente pesquisa do IBGE, no ano de 2017 o Brasil gerou 1,8 milhão de novos postos de emprego, porém sem carteira assinada e em vagas de menor salário, de tal modo que hoje o número de trabalhadores sem carteira assinada supera os empregados com vínculo celetista formalizado. ${ }^{46} \mathrm{Em}$ outras palavras, trata-se da precarização selvagem que a Reforma traduz na questão da empregabilidade. Empregos informais não são vagas criadas, são subempregos, vagas precarizadas, que só aumentam o risco do trabalhador e dos próprios empregadores, que permanecem em um cenário de incertezas. Emprego sem décimo terceiro, sem férias, sem horas extras, sem proteção ao ambiente de trabalho, esta é a matriz reformista. Mesmo assim, o país conta, ainda, com mais de 12 milhões de desempregados, o que reforça a tese de que a Reforma Trabalhista, que seria a nova salvadora da Pátria, só fez piorar o mercado de trabalho, que vinha em um crescente contínuo ao longo do ano de 2017, na vigência da antiga legislação.

\footnotetext{
${ }^{44}$ Segundo a expressão de Ricardo Antunes, a "classe-que-vive-do-trabalho" (Os sentidos do trabalho. Ensaio sobre a afirmação e negação do trabalho. 2. ed. São Paulo: Boitempo, 2009. p. 206).

45 Ibidem, p. 207.

${ }^{46}$ FOLHA DE SÃO PAULO. Informalidade se consolida como motor da recuperação do emprego. Disponível em: https://www1. folha.uol.com.br/mercado/2018/02/1954907-informalidade-se-consolida-como-motor-da-recuperacao-do-emprego. shtml?utm_source=facebook\&utm_medium=social\&utm_campaign=compfb. Acesso em: 6 fev. 2018.
} 
Mais do que uma crise de empregos, vive-se uma crise do que é o próprio trabalho e que possui estreita ligação com este novo paradigma flexibilizador e tecnológico em que se centra o Direito do Trabalho na lógica reformista.

\subsection{Inovação}

Uma das deficiências da legislação trabalhista e que veio regulamentada pela Reforma Trabalhista foi a questão do teletrabalho, esta possibilidade de o empregado, mantendo a relação subordinada com seu empregador, desenvolver as suas atividades fora do ambiente laboral típico. Trata-se de um ponto bastante salutar, em vista da crescente relação que o desenvolvimento tecnológico possui com a Ciência Jurídica, e, aqui, em especial o Direito do Trabalho.

É inegável que a relação entre Direito e técnica não ratifica apenas uma relação pautada pela conjunção "e". Não se trata aqui de estudar apenas o Direito e a técnica, mas sim constatar que o Direito é parte da própria técnica. O Direito serve como forma de proteger o "homem das fantasias de onipotência geradas pela potência das máquinas". ${ }^{47}$ O que se verifica é a existência de questionamentos levantados pelas novas tecnologias, que provocam o Direito, sem fazê-lo desaparecer neste cenário, senão pelo contrário, a provocação da técnica ao Direito evidencia que ele se encontra atrasado em definições relativamente ao progresso técnico e que não pode querer submeter os avanços científicos a princípios jurídicos de caráter imutável. Agora já não mais falando em Direito e técnica, mas sim Direito enquanto técnica, desvela-se a necessidade de tornar o seu conteúdo um reflexo dos avanços tecnológicos a partir de valores humanos.

Neste sentido, Mattos e Guimarães compreendem que a geração de emprego e renda com base em atividades de ciência, tecnologia e inovação ainda é um tema controvertido e polêmico, porquanto o aumento dos sistemas de produção provocado pela ampliação da importância do conhecimento é uma forma de alavancar a relação entre capital e trabalho. ${ }^{48}$ Nesta relação complexa, o ser humano deixa de ser um simples operador e passa a assumir tarefas novas, marcadas pelo uso intenso do conhecimento, gerando consequências econômicas, sociais, filosóficas e ideológicas que rompem com os pilares básicos do processo de desenvolvimento.

O uso da ciência, tecnologia e inovação como fator de geração de empregos se desvela, desta forma, a partir de três pilares, dentro da visão exposta por Mattos e Guimarães: a) o desenvolvimento de um produto inovador, de grande valor agregado e intensivo em conhecimentos gerados; b) um processo inovador, como um conjunto de procedimentos e tecnologias que compõem um sistema produtivo e eficaz em conhecimento direto; c) um empreendimento inovador, ou seja, uma organização composta por pessoas, processos, produtos, gestão e cultura gerados pelo processo de ciência, tecnologia e inovação. ${ }^{49}$

\footnotetext{
${ }_{47}$ SUPIOT, Alain. Homo juridicus: ensaio sobre a função antropológica do Direito. Tradução Maria Ermantina de Almeida. São Paulo: Martins Fontes, 2007. p.144.

48 MATTOS, João Roberto Loureiro de; GUIMARÃES, Leonam dos Santos. Gestão da tecnologia e inovação: uma abordagem prática. 2. ed. São Paulo: Saraiva, 2012. p.12-13.

49 Ibidem, p. 16.
} 
Destarte, os autores apontam, pelo menos, quatro estratégias para o processo de geração de emprego e renda por meio da ciência, tecnologia e inovação, como o desenvolvimento de laboratórios de pesquisa em universidades, permitindo uma aplicação eficaz dos investimentos em ciência e tecnologia; os institutos de pesquisa e desenvolvimento, com a geração de novos conhecimentos que se transformem em resultados e benefícios para a sociedade; os centros de pesquisa e desenvolvimento de empresas, em que estas dialoguem com as instituições científicas e tecnológicas para a criação da cultura da inovação, atingindo novos mercados e gerando emprego e renda e, por fim, as incubadoras de empresas e parques tecnológicos, como ambientes de inovação que oferecem condições para transformar o conhecimento em produtos, transferindo-se o conhecimento científico para as tecnologias de mercado, desenvolvendo-se talentos com a criação de produtos com valores altamente agregados.

Trata-se do desenvolvimento de conhecimentos e condições para a geração de empregos e renda a partir do empreendedorismo inovador, em que o desenvolvimento tecnológico cria novas condições do desenvolvimento do trabalho, e, por conseguinte, um repensar da gestão destes contratos de trabalho, mantidos com empregados que assumam uma visão inovadora, inspiradora e ousada, em que não apenas o trabalho manual se torne o exemplo da criação de renda e identificação do trabalhador no seio social, mas em que o conhecimento se torne mola propulsora de processos inovadores de ampliação do mercado de trabalho.

Quando o capital procura restabelecer seu ciclo, reorganizando e reestruturando o processo produtivo, os trabalhadores são atingidos material e subjetivamente. O plano material engloba as mencionadas formas de trabalho precário, parcial, terceirizado, subcontratado, no que se pode nominar subproletarização. O plano subjetivo abarca a transição da acumulação rígida para a flexível, provocando transformações na essência e nas representações do trabalho, assim como na consciência dos indivíduos. ${ }^{50} \mathrm{~A}$ reorganização produtiva também é um período de transição na forma de acumulação. O modelo anterior, fordista, dá conta de um conjunto de práticas de controle e disciplina da força de trabalho, tecnologias, produção em massa de mercadorias, estruturada de forma homogênea e vertical, práticas de consumo, e respectivas configurações de poder político e econômico próprios do período pós-guerra. Com a crise mundial iniciada em 1973, o modelo fordista entra em colapso e cede lugar a um período de mudanças rápidas, pleno de incertezas e fluidez. ${ }^{51}$

Este novo cenário, inovador, até mesmo disruptivo, vai demandar cada vez mais a atuação conjunta de empregados e empregadores na proteção ao ambiente de trabalho saudável. Pode-se afirmar até mesmo a gênese de um novo conceito pela Lei no. 13.467/2017, o de teleambiente de trabalho, que, igualmente, demandará uma postura do poder Judiciário, afinal, não serão mais raras as discussões sobre eventual responsabilidade civil do empregador nos casos de acidente de trabalho sofridos pelos trabalhadores a distância. É um ponto que ainda é bastante obscuro e que merecerá atenção daqui para a frente.

\footnotetext{
${ }^{50}$ ANTUNES, Ricardo. Adeus ao trabalho? Ensaio sobre as metamorfoses e a centralidade do mundo do trabalho. São Paulo: Cortez, 2006.

${ }^{51}$ HARVEY, David. Condição pós-moderna. São Paulo: Loyola, 2012.
} 


\section{Democracia}

\subsection{Autonomia}

É no princípio da autonomia que se assenta o maior discurso da Reforma Trabalhista, em que os sujeitos da relação de trabalho assumiriam posição paritária nas condições de execução do seu contrato de trabalho. No novo modelo que se delineia, trabalhadores e trabaIhadoras devem se adaptar às exigências impostas pela flexibilização do mercado, ajustando-se às suas atividades laborais e à plena disponibilidade que lhes é exigida para adequar-se às flutuações de demanda. ${ }^{52}$ Com a acumulação flexível surge um novo modelo de constrição do tempo no âmbito capitalista, resultando no aumento da flexibilidade e da mobilidade das relações laborais. Os empregadores podem, a partir de então, controlar com maior pressão a força de trabalho, desorganizada e enfraquecida. ${ }^{53}$

O novo padrão acumulativo compatibiliza componentes de continuidade e de descontinuidade quanto ao padrão anterior. Com a incorporação de técnicas de gestão da força de trabalho e tecnologias relativas à era da informação, o novo modelo descentraliza a produção, tornando a estrutura mais flexível, e aumenta a exploração da força de trabalho, ampliando sua intensidade. Em igual passo, promove a desregulamentação dos direitos trabalhistas, aumenta a fragmentação no interior da classe trabalhadora, incentiva a terceirização e a desvalorização da mão de obra e desagrega a organização sindical combativa.

O que se tem como um primeiro cenário, ainda incipiente, da Reforma Trabalhista, é que haverá, a curto e médio prazos, uma ressignificação do conceito de subordinação no trabalho, que deixará de ter a feição tradicional do poder de direção, controle e fiscalização rumo a um conceito integrativo do trabalhador na engrenagem econômico-empresarial, que revela a necessidade de adaptação da norma às exigências sociais, sem, no entanto, autorizar uma desarticulação do princípio protetivo, mas que seja mais eficiente na gestão da força laboral.

O contrato de trabalho, e o próprio Direito do Trabalho, são tidos pela ampla doutrina como figuras de Direito Privado. Na verdade, pensa-se que o contrato de trabalho guarda muito mais características de um contrato de adesão do que um contrato paritário. $\mathrm{O}$ empregado, no momento da contratação, não possui nenhum poder para discutir o seu salário, a sua jornada ou outro aspecto da relação. A ele, cabe aceitar todas as condições que lhe são impostas. Por tal razão, o discurso comemorativo de que a Reforma coloca empregados e empregadores em patamar de igualdade deve ser totalmente desconsiderado. A história do Direito do Trabalho sempre justificou com base científica a condição de inferioridade do empregado diante do seu empregador, que, hoje, traduz-se na noção jurídica de poder diretivo. A Reforma não muda este cenário. Mantém o empregado em posição de hipossuficiência e ainda permite que possa negociar com o seu empregador, sem muitas vezes até mesmo conhecer as condições do que está negociando. A estrada segura sempre conduz a alguma chegada. E o caminho mais fácil, às vezes, termina na beira do abismo.

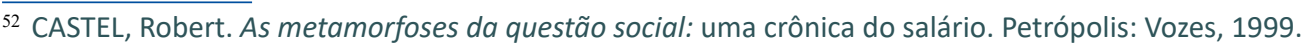

${ }^{53}$ HARVEY, David. Condição pós-moderna, op. cit.
} 


\section{CONSIDERAÇÕES FINAIS}

Sabe-se que o trabalho exerce importante papel na vida das pessoas, seja para sobrevivência ou para desenvolvimento pessoal, profissional ou até mesmo social. A continuidade da relação de emprego, além de ser uma vertente teórica do Direito do Trabalho, é conveniente tanto para o empregador quanto para o empregado. Para este, desvela-se uma necessidade, porque fonte de sua subsistência, mediante o salário pago pelo serviço prestado. Para o empregador, porque lhe traz a tranquilidade de poder contar com a força de trabalho do empregado, direcionando-o para os fins da empresa.

Com o objetivo de adequar os direitos de ordem pública dos trabalhadores aos princípios gerais da atividade econômica, como a valorização social do trabalho e da livre iniciativa, a função social da propriedade e política de pleno emprego, o Direito do Trabalho procurou a renovação de sua efetividade na sociedade, com vistas a se readequar ao novo cenário político-econômico brasileiro. Esta nova postura traz consequências bastante relevantes para a sua área que cuida das relações coletivas. Com o reconhecimento estatal dos acordos e convenções coletivas, bem como da obrigatoriedade da participação dos sindicatos nas negociações, passam os entes sindicais a terem que observar também a Constituição Federal para a produção de normas jurídicas, inserindo o princípio da dignidade da pessoa humana no processo de tomadas de decisão, o que vem a acarretar na presença de certos limites à prática flexibilizatória de normas trabalhistas.

O Direito do Trabalho e o sistema econômico encontram-se em contato permanente desde o fenômeno da Revolução Industrial, o qual tomou forma no início do século 18, servindo a disciplina trabalhista como um contrapeso ao capital, que tende à busca pela lucratividade com o mínimo investimento possível. Neste atual cenário político-econômico brasileiro, o legislador constituinte buscou encontrar o equilíbrio entre o sistema econômico e a proteção social, instituindo limites de ordem pública e permitindo, em alguns casos, a flexibilização de direitos trabalhistas com vistas a atender às necessidades de adaptação das relações específicas que o Direito já não mais consegue controlar.

No atual momento histórico encontramo-nos diante do desafio de restabelecer o curso do desenvolvimento, configurando um novo modelo político em que o Estado, já despido do papel de protagonista maior, transfere para a sociedade grande parte da responsabilidade pelo desempenho em iniciativas de diminuição das desigualdades e melhoria da qualidade de vida, sem ignorar o papel que o mercado e a iniciativa privada têm. Por tais razões, reflete-se no sentido de que, para as empresas atingirem a sua função social, que é a de gerar empregos e movimentar a economia, concessões devem ser efetuadas, muitas delas até mesmo autorizadas pelo Direito do Trabalho, como as negociações coletivas e a própria possibilidade de redução salarial.

Deve-se ter em mente, porém, que o debate acerca do desenvolvimento econômico a partir da Reforma Trabalhista está longe de ser esgotado. A resistência da sociedade em relação à Reforma consiste na tentativa de conter o avanço da precarização nas relações laborais e a erosão nos direitos dos trabalhadores e não naquela velha dicotomia empregados contra empregadores, a ser sempre substituída pelo caráter de cooperação nas relações laborais. 


\section{REFERÊNCIAS}

AGUIAR JUNIOR, Ruy Rosado. A boa-fé na relação de consumo. Revista de Direito do Consumidor, São Paulo: Revista dos Tribunais, n. 14, p. 20-32, abr./jun. 1995.

ANTUNES, Ricardo. Adeus ao trabalho? Ensaio sobre as metamorfoses e a centralidade do mundo do trabalho. São Paulo: Cortez, 2006.

BARROS, Alice Monteiro. Curso de direito do trabalho. 9. ed. São Paulo: LTr. 2013.

CASTEL, Robert. As metamorfoses da questão social: uma crônica do salário. Petrópolis: Vozes, 1999.

DELGADO, Mauricio Godinho. Curso de direito do trabalho. 9. ed. São Paulo: LTr, 2010.

DIAS, Carlos Eduardo Oliveira. Entre os cordeiros e os lobos: reflexões sobre os limites da negociação coletiva nas relações de trabalho. São Paulo: LTr. 2009.

FOLHA DE SÃO PAULO. Informalidade se consolida como motor da recuperação do emprego. Disponível em: https://www1.folha.uol.com.br/mercado/2018/02/1954907-informalidade-se-consolida-como-motor-da-recuperacao-do-emprego.shtml?utm_source=facebook\&utm_medium=social\&utm_campaign=compfb. Acesso em: 6 fev. 2018.

GÓIS, Luiz Marcelo Figueiras de. A caminho de um direito trabalhista constitucional. São Paulo: LTr, 2010.

HARVEY, David. Condição pós-moderna. São Paulo: Loyola, 2012.

MANUS, Pedro Paulo Teixeira. Negociação coletiva e contrato individual de trabalho. São Paulo: Atlas, 2001.

MARQUES, Cláudia Lima. Contratos no Código de Defesa do Consumidor: o novo regime das relações contratuais. 3. ed. São Paulo: Revista dos Tribunais, 1998. (Biblioteca de Direito do Consumidor, v. 1).

MARTINS, Sérgio Pinto. Direito do trabalho. 29. ed. São Paulo: Atlas, 2013. p. 6.

MATTOS, João Roberto Loureiro de; GUIMARÃES, Leonam dos Santos. Gestão da tecnologia e inovação: uma abordagem prática. 2. ed. São Paulo: Saraiva, 2012.

MILIBAND, Ralph. Análise de classes. In: GIDDENS, Anthony; TURNER, Jonathan (org.). Teoria social hoje. São Paulo: Unesp, 1999.

NEGREIROS, Teresa. Teoria do contrato: novos paradigmas. 2. ed. Rio de Janeiro: Renovar, 2006.

PERLINGIERI, Pietro. Perfis do direito civil. 3. ed. rev. e ampl. Rio de Janeiro: Renovar, 2002.

SANTOS, Ronaldo Lima dos. Teoria das normas coletivas. 2.ed. São Paulo: LTr, 2009.

SUPIOT, Alain. Homo juridicus: ensaio sobre a função antropológica do Direito. Tradução Maria Ermantina de Almeida. São Paulo: Martins Fontes, 2007.

TEPEDINO, Gustavo. Crise das fontes normativas e técnica legislativa na Parte Geral do Código Civil de 2002. In: TEPEDINO, Gustavo (org.). A parte geral do novo código civil: estudos nas perspectiva civil-constitucional. 2. ed. Rio de Janeiro: Renovar, 2003.

TEPEDINO, Gustavo. Normas constitucionais e Direito Civil. Revista da Faculdade de Direito de Campos, ano IV, $\mathrm{n}$. 4 e ano V, n. 5, 2003-2004.

VIANA, Segadas. Antecedentes históricos. In: SÜSSEKIND, Arnaldo Lopes et al. Instituições de direito do trabalho. 22. ed. atualizada por Arnaldo Süssekind e João de Lima Teixeira Filho. São Paulo: LTr, 2005. 